Western University

Scholarship@Western

Aboriginal Policy Research Consortium International (APRCi)

6-2012

Cannabis use in Cape York Indigenous communities: High prevalence, mental health impacts and the desire to quit

India Bohanna

James Cook University

Alan R. Clough

James Cook University

Follow this and additional works at: https://ir.lib.uwo.ca/aprci

Part of the Other Public Health Commons, and the Substance Abuse and Addiction Commons

Citation of this paper:

Bohanna, India and Clough, Alan R., "Cannabis use in Cape York Indigenous communities: High prevalence, mental health impacts and the desire to quit" (2012). Aboriginal Policy Research Consortium International (APRCi). 409.

https://ir.lib.uwo.ca/aprci/409 


\title{
Cannabis use in Cape York Indigenous communities: High prevalence, mental health impacts and the desire to quit
}

\author{
INDIA BOHANNA \& ALAN R. CLOUGH
}

School of Public Health, Tropical Medicine and Rehabilitation Sciences, fames Cook University, Cairns, Australia

\begin{abstract}
Introduction and Aims. Anecdotal reports suggest that high rates of cannabis use and dependence are significant issues in Indigenous communities in north Queensland; however, there is little scientific evidence to support or refute this. The Cape York Cannabis Project seeks to investigate cannabis use rates, cannabis dependence and mental health impacts for the first time in three Cape York Indigenous communities. Design and Methods. The current study reports preliminary findings, resulting from interviews with 133 Indigenous participants aged 14-47 years from one Cape York community. Quantitative data were gathered on rates of cannabis use, cannabis dependence as measured by a score of $\geq 3$ the Severity of Dependence Scale. Qualitative self-report data were gathered concerning mental health impacts of cannabis and reasons for quitting. Results and Conclusions. Very high rates of cannabis use were identified, with $66.2 \%$ of males and $30.5 \%$ of females interviewed being current users. An additional $12.2 \%$ of males and $30.5 \%$ of females were former users, and $21.6 \%$ of males and $39 \%$ of females had never used cannabis. High rates of cannabis dependence were also observed. Of those current users who used cannabis at least weekly, 67.7\% reported cannabis dependence. A range of mental health impacts due to cannabis were reported. In total, $76.1 \%$ of current users were considering quitting or cutting down. Rates of use and dependence were much higher than national rates, and indicate significant mental health harms due to cannabis. Further investigation of mental health impacts of cannabis is required, as is intervention to reduce these impacts. [Bohanna I, Clough AR. Cannabis use in Cape York Indigenous communities: High prevalence, mental health impacts and the desire to quit. Drug Alcohol Rev 2012;31:580-584]
\end{abstract}

Key words: cannabis, mental health, Indigenous population.

\section{Introduction}

More Indigenous than non-Indigenous Australians use cannabis; however, the level and impacts of cannabis use in remote Indigenous communities are just becoming appreciated [1]. According to the most recent national survey, $4.9 \%$ of males and $2.2 \%$ of females aged $\geq 14$ years reporting cannabis use in the past week [2]. In contrast, rates of cannabis use may be much higher in remote Indigenous communities. Recent studies of communities in Arnhem Land (Northern Territory) indicate that $60 \%$ or more of those surveyed used cannabis at least weekly $[3,4]$. These high rates of use compared to the national data support anecdotal evidence that cannabis may be a significant issue in remote north Queensland Indigenous communities [5]; however, there is currently no scientific evidence to support or refute this.

Indigenous Australians suffer poorer mental health compared with non-Indigenous Australians, which may be linked to higher rates of cannabis use in Indigenous communities $[1,6,7]$. Indigenous Australians are four to five times more likely than other Australians to be hospitalised for mental or behavioural disorders because of psychoactive substance use [8]. High rates of cannabis use have been linked to hallucinations, suicidal ideation, depression and anxiety in Indigenous individuals in the Northern Territory $[7,9,10]$. A recent study investigating psychosis in Indigenous individuals from remote north Queensland communities revealed that cannabis

India Bohanna, PhD, Research Officer, Alan R. Clough, PhD, Principal Research Fellow. Correspondence to Dr India Bohanna, James Cook University (Cairns Campus), McGregor Road, Smithfield, Qld 4870, Australia. Tel: +61 074042 1691; Fax: +61 0740421492 ; E-mail: india.bohanna@jcu.edu.au

Received 8 September 2011; accepted for publication 19 November 2011. 
contributed to psychosis onset in $52 \%$ of cases, and was impacting current clinical condition in $32 \%$ of cases [11].

The Cape York Cannabis Project was developed to investigate cannabis use rates and impacts in northern Queensland Indigenous communities. The aim of this communication is to report preliminary data from this project, providing the first data on cannabis use rates, cannabis dependence and other mental health impacts in remote north Queensland Indigenous communities.

\section{Methods}

Participants were opportunistically recruited in one alcohol-restricted Cape York community between July 2010 and March 2011. Individuals were eligible for inclusion in the study if they were aged between 14 and 50 years and were currently residing in the community. This age range was chosen based on previous evidence from remote communities in Arnhem Land, which indicated that most cannabis users were within this age range [12]. Exclusion criteria were the presence of mental illness or non-resident status within the community. Potential participants were approached at various locations in the community (e.g. community council office, health centre and community farm), the study was explained to interested individuals, and those eligible were given written information about the study and invited to participate. Informed written consent was obtained prior to interview. Approval was provided by James Cook University and Cairns and Hinterland Human Ethics Committees.

During structured interviews, participants were asked to report their current status with regard to cannabis use. 'Current' users were those that had used cannabis any time in the preceding 6 months. 'Former' users were those who had used cannabis, but not in the preceding 6 months. 'Never' users had never used cannabis. For current users, frequency of use was documented: daily, at least once per week but less often than daily (weekly), less often than once a week (less than weekly). Approximate date of first and last use was recorded. In addition, the Severity of Dependence Scale (SDS) $[13,14]$ was administered to current users to determine cannabis dependence. Individuals scoring $\geq 3$ on the SDS were considered dependent [14].

Current cannabis users were asked to report the number of times they had tried to quit and about any intentions to quit or cut down in future and the reason for wanting to do so.

Potential mental health impacts of cannabis use were investigated qualitatively. Consistent with a responsive 'research yarning' approach [15], current and former users were asked the following open-ended question: 'have you had any mental health problems from cannabis?' In order to determine potential cannabis withdrawal symptoms, participants were asked: 'how do you feel when you run out of cannabis or can't get any cannabis?' All participants were asked if they smoked tobacco.

\section{Results}

A total of 133 Indigenous people (74 males and 59 females) were interviewed (Table 1), which represents $28 \%$ of the community population within the target age range. We found high rates of cannabis use and dependence. In total, $66.2 \%$ of males and $30.5 \%$ of females interviewed were current users, $12.2 \%$ of males and $30.5 \%$ of females were former users and $21.6 \%$ of males and $39 \%$ of females had never used cannabis. Within the group of current users, $37.3 \%$ were using

Table 1. Demographic information

\begin{tabular}{|c|c|c|c|}
\hline & $\begin{array}{l}\text { Current users } \\
\quad(n=67)\end{array}$ & $\begin{array}{l}\text { Former users } \\
\quad(n=27)\end{array}$ & $\begin{array}{l}\text { Never users } \\
\quad(n=39)\end{array}$ \\
\hline Male : female & 49:18 & $9: 18$ & $16: 23$ \\
\hline Age: mean (range) & $27.2(15-47)$ & $28.0(18-39)$ & $25.2(14-45)$ \\
\hline Age of first use: mean (range) & $15.9(8-37)$ & $16.3(13-22)$ & N/A \\
\hline \multicolumn{4}{|l|}{ Frequency of cannabis use (\%) } \\
\hline Daily & 37.3 & N/A & N/A \\
\hline Weekly & 34.3 & & \\
\hline Less often than weekly & 28.4 & & \\
\hline \multicolumn{4}{|l|}{ Cannabis dependent $(\%)^{\mathrm{a}}$} \\
\hline Daily & 64.0 & N/A & N/A \\
\hline Weekly & 65.2 & & \\
\hline Less often than weekly & 63.2 & & \\
\hline Current tobacco user (\%) & 97.4 & 58.8 & 69.2 \\
\hline
\end{tabular}

${ }^{a}$ Dependence: $\geq 3$ on the Severity of Dependence Scale. N/A, not applicable. 
Table 2. Reasons for quitting or wanting to quit in current and previous cannabis users

\begin{tabular}{|c|c|c|c|}
\hline & $\begin{array}{l}\text { Current \% } \\
(n=67)\end{array}$ & $\begin{array}{c}\text { Former } \% \\
(n=27)\end{array}$ & $\begin{array}{l}\text { Total \% } \\
(n=94)\end{array}$ \\
\hline Starting a job ('wanted to get into the army', 'got a new job') & 26.9 & 11.1 & 22.3 \\
\hline Mental health ('stressing out', 'would think about hurting myself') & 4.5 & 14.8 & 7.5 \\
\hline Financial ('cost too much', 'couldn't afford it anymore') & 3.0 & 11.1 & 5.3 \\
\hline
\end{tabular}

Table 3. Mental health impacts of cannabis use reported in current and previous cannabis users

\begin{tabular}{lccc}
\hline & $\begin{array}{c}\text { Current \% } \\
(n=67)\end{array}$ & $\begin{array}{c}\text { Former \% } \\
(n=27)\end{array}$ & $\begin{array}{c}\text { Total \% } \\
(n=94)\end{array}$ \\
\hline $\begin{array}{l}\text { 'Stressing out' when } \\
\text { cannabis unavailable }\end{array}$ & 22.4 & 25.9 & 23.4 \\
$\begin{array}{l}\text { Anger/irritability } \\
\text { Thoughts of self-harm/ }\end{array}$ & 9.0 & 7.4 & 8.5 \\
$\quad$ suicide & 6.0 & 0.0 & 4.3 \\
$\begin{array}{l}\text { Paranoia } \\
\text { Hearing things }\end{array}$ & 4.5 & 3.7 & 4.3 \\
$\begin{array}{l}\text { Memory impairment } \\
\text { Depression }\end{array}$ & 3.0 & 7.4 & 4.3 \\
& 6.0 & 0.0 & 4.3 \\
& 3.0 & 0.0 & 2.1 \\
\hline
\end{tabular}

cannabis daily, $34.3 \%$ were using cannabis less often than daily but at least weekly, and $28.4 \%$ were using cannabis less often than once per week. Dependence was similar for daily, weekly and less than weekly users, as measured by a score of $\geq 3$ on the SDS: $64 \%$ for daily users, $65.2 \%$ for those using at least weekly and $63.2 \%$ for those using less often than weekly. Early onset use was common, with a mean age of first use of 15.9 years among current users, and 16.3 among former users. Mean duration of use for current users was 11.4 years and 11.6 for former users. In total, $97.4 \%$ of current cannabis users were using tobacco compared to $58.8 \%$ of former users and $69.2 \%$ of never users.

Among current users, $76.1 \%$ were considering quitting or cutting down, and $73.1 \%$ had made at least one previous attempt to quit. As shown in Table 2, in current users, seeking, starting or maintaining employment was the most common motivation for quitting $(26.9 \%)$, while former users quit primarily for family reasons $(48.2 \%)$.

As shown in Table 3, both current and former users reported negative mental health impacts of cannabis use. Most commonly reported was 'stressing out' when cannabis was not available (23.4\%), suggesting symptoms of cannabis withdrawal. Anger or irritability was reported in $8.5 \%$ of current or former users and $4.3 \%$ reported one or more of paranoia, hearing voices, thoughts of suicide/self-harm and memory impairment. Mental health was the joint second most reported reason for quitting in former users $(14.8 \%)$ along with lost desire.

\section{Discussion}

For the first time, rates of cannabis use and the associated negative mental health impacts have been documented in a Cape York Indigenous community. Very high rates of use and dependence were observed, and many current users may be suffering negative mental health impacts because of their cannabis use. This study is a first step in addressing community concerns about cannabis and requests for improved understanding of cannabis use and its related mental health harms [4]. Indigenous community leaders have attributed to cannabis a range of mental health effects, including psychosis, dependence and suicide [5], and our findings provide support for these concerns. Findings of poor mental health are concerning considering that individuals in remote communities have reduced access to medical and psychiatric services [16]. Such services are clearly required to address these high rates of cannabis dependence and negative mental health impacts.

The observed cannabis use and dependence rates, as well as the mental health harms, are similar to those observed in Northern Territory remote communities $[3,9,10]$. This suggests interventions to reduce cannabis and its psychiatric effects are urgently needed in northern Australian Indigenous communities, both in Queensland and the Northern Territory. We found that three out of four current users are considering quitting or cutting down, which suggests that strategies to enhance quit support should be developed. Given that many users quit for family reasons, strategies that strengthen and empower families and use the family network to support quit attempts may be effective.

More comprehensive and systematic investigation of the mental health harms associated with cannabis 
is required. This high-priority research requires assessment instruments that are both culturally acceptable and psychometrically validated, and while the number of instruments validated for use with Indigenous Australian individuals is increasing there is considerable work to be done [17]. For example, validated instruments to comprehensively assess psychotic symptoms in Indigenous individuals are needed. The development of such tools will be a significant step towards enabling the comprehensive and reliable assessment of cannabis-related harms. In addition, the holistic Indigenous concept of social and emotional well-being, integrating physical, psychological, social, historical and environmental aspects [17] is consistent with our finding that many individuals wanted to quit for family reasons.

The findings must be interpreted in light of the limitations the study. Opportunistic sampling may have lead to bias if a certain group of individuals were less likely to participate (e.g. underrepresentation of cannabis users). Nevertheless, we surveyed $28 \%$ of individuals within the target age range from community therefore we are confident that the results are representative. In addition, the study used a qualitative selfreport approach to gathering mental health data, by asking open-ended questions. This method has highlighted concerning findings about the mental health impacts of cannabis; however, it is clear that symptoms of mental ill health must be assessed more systematically in both users and non-users, in order to understand the true prevalence and severity of mental ill health due to cannabis. Also, participants were not asked about alcohol use as the community had alcohol restrictions in place. Nevertheless, it is possible that alcohol consumption has affected participant's mental health; therefore, future studies should address these factors explicitly. Finally, the findings reported here are preliminary. Data are currently being collected in other communities to provide a more comprehensive picture of cannabis use in Cape York Indigenous communities.

The lack of data on mental health in Indigenous communities has been highlighted, along with the need to support mental health programs and interventions with systematic research $[6,18]$. Assessment of the mental health impacts of cannabis use within Cape York Aboriginal communities using culturally valid, rigorous methods is needed. This will provide the evidence base urgently required to develop effective early detection, intervention and prevention programs targeting cannabis and mental health. Such evidence-based early interventions and preventative approaches to mental health and illicit drug use are crucial to confer longlasting, sustainable mental health benefits to Indigenous Australians. The finding that more than three-quarters of participants wanted to quit or cut down suggests significant opportunities for interventions to enhance quit support. It may also be useful to determine what lessons can be learned from former heavy alcohol users, in terms of their reasons and strategies for quitting.

\section{Acknowledgements}

This research was funded by the National Health and Medical Research Council through project grant 601002. The authors acknowledge the contributions of the research team: Ms Jan Robertson, Ms Bernadette Rogerson, Mr Ray Genn, Mr Eddie Buli, Mr Lomas Amini, Ms Celia Demarchi and Ms Veronica Graham. The study participants are also acknowledged.

\section{References}

[1] Lee K, Conigrave K, Patton G, Clough A. Cannabis: endemic yet neglected in remote Indigenous Australia. Med J Aust 2009;190:228-9.

[2] Australian Institute of Health and Welfare. 2007 National Drug Strategy Household Survey: detailed findings. Canberra: AIHW, 2008.

[3] Lee KS, Clough AR, Conigrave KM. High levels of cannabis use persist in Aboriginal communities in Arnhem Land, Northern Territory. Med J Aust 2007;187:594-5.

[4] Clough A, D'Abbs P, Cairney S, et al. Emerging patterns of cannabis and other substance use in Aboriginal communities in Arnhem Land, Northern Territory: a study of two communities. Drug Alcohol Rev 2004;28:381-90.

[5] Robertson J, Dowie R. A cloud over our community. Of Substance 2008;6:28-9.

[6] Swan P, Raphael B. 'Ways forward': national Aboriginal and Torres Strait Islander mental health policy national consultancy report. Canberra: AGPS, 1995.

[7] Dingwall K, Cairney S. Detecting psychological symptoms related to substance use among Indigenous Australians. Drug Alcohol Rev 2011;30:33-9.

[8] Australian Institute of Health and Welfare. Aboriginal and Torres Strait Islander Health Performance Framework, 2006 report: detailed analyses. Canberra; 2007.

[9] Clough AR, Lee KSK, Cairney S, et al. Changes in cannabis use and its consequences over 3 years in a remote indigenous population in northern Australia. Addiction 2006;101:696-705.

[10] Lee KS, Clough AR, Jaragba MJ, Conigrave KM, Patton GC. Heavy cannabis use and depressive symptoms in three Aboriginal communities in Arnhem Land, Northern Territory. Med J Aust 2008;188:605-8.

[11] Hunter E, Gynther B, Anderson C, Onnis L, Groves A. Psychosis and its correlates in a remote Indigenous population. Australas Psychiatry 2011;19:434-8.

[12] Clough AR, Guyula T, Yunupingu M, Burns CB. Diversity of substance use in eastern Arnhem Land (Australia): patterns and recent changes. Drug Alcohol Rev 2002;21: 349-56.

[13] Gossop M, Darke S, Griffiths P, et al. The Severity of Dependence Scale (SDS): psychometric properties of the SDS in English and Australian samples of heroin, cocaine and amphetamine users. Addiction 1995;90:607-14.

[14] Martin G, Copeland J, Gates P, Gilmour S. The Severity of Dependence Scale (SDS) in an adolescent population of 
cannabis users: reliability, validity and diagnostic cut-off. Drug Alcohol Depend 2006;83:90-3.

[15] Power K. Yarning: a responsive research methodology. J Aust Res Early Childhood Ed 2004;11:37-46.

[16] Hunter E. Disadvantage and discontent: A review of issues relevant to the mental health of rural and remote Indigenous Australians. Aust J Rural Health 2007;15:88-93.
[17] Dingwall KM, Cairney S. Psychological and cognitive assessment of Indigenous Australians. Aust N Z J Psychiatry 2010;44:20-30.

[18] NHMRC. The NHMRC Road map: a strategic framework for improving aboriginal and torres strait islander health through research. Canberra; 2002. 